\title{
JORNALISTAS DA ECONOMIA E HOMENS DAS FINANÇAS: Fascinação, ASCEndênCIA E ILUSÃo PROFissional
}

\author{
Tomas UNDURRAGA* \\ Antonio José PEDROSO NETO**
}

\begin{abstract}
RESUMO: Objetivo do texto: explorar as relações dos jornalistas da economia com agentes do campo econômico e do campo dos economistas como hierarquizantes de perspectivas sobre a economia. Analisamos 58 entrevistas com jornalistas. Partimos da noção de illusio (Pierre Bourdieu) e exploramos o engajamento deles no trabalho: o engajamento a partir da noção de furo; os meios para os furos mais importantes, as fontes; e a formação das perspectivas sobre a economia. Procuramos revelar as posições de suas fontes e formadores nos dois campos. Resultados: a ideia de "mexer com o mercado" hierarquiza textos e autores; fontes de prestígio perpassaram governos, instituições financeiras e são do espaço finanças; jornalistas estabelecem relações de reciprocidade com agentes desse espaço, conseguem furos, entrevistas; realizam a illusio da profissão e estabelecem posições centrais no jornalismo econômico; os modos de aprendizagem e especialização em economia indicam ascendência dos agentes desse espaço, agentes dominantes no mundo econômico.
\end{abstract}

PALAVRAS-CHAVE: Jornalismo econômico. Elites. Illusio. Economistas. Finança.

\section{Introdução}

Nosso objetivo neste texto é explorar as relações dos jornalistas da elite do jornalismo econômico brasileiro (JEB) com agentes eficientes (BOURDIEU, 2000) do campo econômico (BOURDIEU, 1997a) brasileiro e do campo dos economistas

\footnotetext{
* UAH - Universidad Alberto Hurtado. Departamento de Sociología. Santiago de Chile, Chile. tundurraga@uahurtado.cl. https://orcid.org/0000-0003-4267-5826.

** UFT - Universidade Federal do Tocantins. Programa de Pós-Graduação em Desenvolvimento Regional (PPGDR) e Programa de Pós-Graduação em Comunicação e Sociedade (PPGCOM). Palmas - TO - Brasil. 77021-050 - ajpedrosoneto@uol.com.br. http://orcid.org/0000-0002-6509-527X.
} 
brasileiros (LOUREIRO, 1997), como um dos fatores que levam à produção e à manutenção de uma hierarquia de perspectivas sobre a economia.

No Brasil, desde o início dos anos 1970, temos um amplo desenvolvimento da parte dos jornais dedicada à economia: o jornalismo econômico. Pedroso Neto (2015), a partir de vários textos - Quintão (1987), Kucinski (1996), Abreu (2003), Caldas (2003), Nassif (2003) -, apresenta uma síntese razoável sobre o desenvolvimento e o lançamento de jornais e revistas especializados, cadernos, equipes, etc. junto com mudanças e diversificações do conteúdo existente até então.

Nesse período, progressivamente, foram estruturadas editorias - ou reestruturadas as poucas existentes - e cadernos de economia em jornais já existentes. Foram fundados ainda, novos jornais, revistas, programas de rádio e televisão dedicados a assuntos da esfera econômica. Ao mesmo tempo, começou a especialização dos jornalistas; o crescimento do pessoal, das rotinas, dos relacionamentos com fontes específicas e dos processos de treinamento e formação de profissionais, todos relacionados a fatos, agentes, instituições e processos da economia (PEDROSO NETO, 2015, p. 136).

Todos esses aparatos da indústria cultural, mais pontualmente dedicada a atividade econômica, se desenvolveram e institucionalizaram de modo que, atualmente, o jornalismo econômico é uma prática de produção simbólica, um bem simbólico (BOURDIEU, 1987a), integrante da nossa vida econômica: participa das lutas simbólicas que visam dar sentido às atividades, práticas, discursos, etc. da economia, mas o conteúdo que é publicado não dá voz e vez a todos os agentes econômicos e a todos os assuntos possíveis. E, o que é mais importante para este texto, não dá voz e vez às diferentes perspectivas sobre a economia. Quer dizer, há uma hierarquia de princípios cognitivos de visão e divisão do mundo - "princípios de divisão que, num momento determinado do tempo, determinam a visão do mundo (rico/pobre, branco/negro, nacional/estrangeiro etc.) e o poder de fazer ver e de fazer crer que lhe é inerente" (BOURDIEU, 2001a, p. 226-227) - operacionalizados pelos jornalistas quando selecionam o conteúdo explícito e implícito objetivados nos textos do jornalismo econômico dominante. Como se produz essa hierarquia?

Desde os anos 1980, temos um processo de expansão, liberdade e sofisticação dos produtos, agentes, empresas e crenças da esfera das finanças que tem dimensão mundial. E, dando suporte a esse processo, temos a predominância da perspectiva e do enquadramento dos acontecimentos da esfera econômica e financeira a partir de crenças e princípios de visão e divisão de mundo chamados de economia ortodoxa 
e/ou neoliberal; expressões de práticas, princípios e preceitos normativos como desregulamentação das atividades econômicas, presença mínima do Estado na economia, ação econômica como ação de indivíduos racionalizadores e utilitaristas, concorrência livre entre agentes e organizações, mercados livres e autorregulados como melhor meio de alocar recursos, etc.

Assim, neste contexto e conforme o objetivo deste texto, temos uma hipótese: os jornalistas dominantes no JEB têm vínculos - confiança, reciprocidade, dependência e poder - com agentes de uma determinada região do campo econômico e dos economistas brasileiros e esses vínculos explicam, em parte, suas posições no JEB e suas relações com a doxa compartilhada por esses agentes: ortodoxia econômica.

Do ponto de vista teórico e metodológico, operacionalizamos a pesquisa a partir de uma perspectiva que trata a mídia a partir da noção de campo (BOURDIEU, 1987a, 1997b; CHAMPAGNE, 2007). Neste sentido, pensamos o JEB como um espaço social (BOURDIEU, 1987a, 2000), um subcampo do jornalismo, produtor bens simbólicos (BOURDIEU, 1987a) particulares - textos como colunas, editorias, reportagens, comentários, análises - que têm influência sobre a sociedade (BOURDIEU, 1987a; CHAMPAGNE, 2000; DUVAL, 2004; TEMMAR, ANGERMULLER e LEBARON, 2013). Pensamos os jornalistas da economia como criadores individuais numa estrutura social; relações no subcampo JEB e relações com o campo do jornalismo e outros campos sociais. Assim, consideramos que os jornalistas, além de agirem vis-à-vis seus pares - campo do jornalismo e subespaço do JEB -, agem em relação a outros agentes sociais, isto é, atuam fortemente em relação ao campo dos economistas brasileiros (LOUREIRO, 1997), ao campo econômico (BOURDIEU, 1997a) e ao campo do poder (BOURDIEU, 1987b, 1989 e 1996).

Portanto, para responder a questão da pesquisa, temos que conhecer quais são os trunfos particulares que explicam as posições dos jornalistas que são da elite, que são dominantes no JEB. E temos que conhecer quais são as ligações dos jornalistas da economia com os agentes, instituições, valores, perspectivas, princípios de visão de mundo do campo econômico e do campo dos economistas brasileiros.

Quais são os trunfos típicos da trajetória dos jornalistas da elite do JEB? Para responder minimamente isso, recorremos a trabalhos que já os pesquisaram e os revelaram: Abreu (2003), Pedroso Neto (2015), Pedroso Neto, Undurraga (2017; no prelo). Os dois últimos, particularmente, apresentam uma análise de correspondências múltiplas de dados prosopográficos de dois conjuntos de jornalistas da economia: um dos que são da elite; e outro dos que não são da elite, mas são da mesma geração mesma idade, mesmo momento de formação e inserção profissional. Essas análises procuram apresentar dados sobre a estrutura do espaço em que se localiza a elite do 
JEB, com o objetivo de revelar e especificar algumas de suas estruturas fundamentais (PEDROSO NETO, UNDURRAGA, 2017; no prelo), também presentes em (ABREU, 2003; PEDROSO NETO, 2015).

Quais são as ligações dos jornalistas da economia com outros campos sociais, com o econômico e o dos economistas em particular? Para responder minimamente a isso, fizemos uma análise de 58 entrevistas com jornalistas de elite e não elite. Partimos da noção de illusio; investimento, encantamento, crença no jogo de um determinado campo devido à sua apreensão a partir das disposições adequadas e próprias daquele campo, adquiridas por experiência prolongada (BOURDIEU, 1997a, 2001a; COSTEY, 2005). E exploraremos que, além dos interesses utilitários, há um engajamento dos jornalistas no trabalho que passa por gosto, encantamento, reconhecimento e crença desconhecida como tal nos princípios e nos jogos constituintes do campo, a "dupla verdade do trabalho" (BOURDIEU, 2001b, p. 247).

Exploramos esse engajamento partindo da noção de furo/ineditismo, algo bem estabelecido no jornalismo contemporâneo e que dinamiza o trabalho dos jornalistas. Exploramos a illusio, analisando a noção de furo (SCHUDSON 1995; STARKMAN 2014), ou seja, os tipos de exclusividade que são mais valorizados no jornalismo econômico brasileiro, são mais reconhecidos no espaço jornalístico, nas opiniões dos jornalistas. Consideramos que jornalistas da elite são influentes na reprodução da hierarquia dos princípios da seleção e orientação próprios do campo. Publicando seletivamente, ao enfatizar algumas opiniões vis-à-vis outras, os jornalistas acabam promulgando, ainda que indiretamente, certos tipos de normas e prescrições econômicas em face de outras. Procuramos revelar os tipos de furos que são característicos do JEB e são melhor posicionados numa hierarquia. Em seguida, procuramos explorar os meios para se realizar os furos mais importantes; as fontes de informações. Procuramos explorar quais são as fontes do JEB - localização no espaço social - e como os jornalistas se relacionam com elas, a partir das suas posições no espaço do JEB. Em seguida, procuramos explorar como os jornalistas da elite formaram suas perspectivas, suas crenças, seus princípios de visão e divisão de mundo sobre a economia. E, por fim, procuramos revelar, as posições das fontes e demais relações sociais dos jornalistas da economia no campo econômico e no campo dos economistas brasileiros.

Essa análise é orientada pela ideia de que os jornalistas da elite - os mais lidos e repercutidos, os com poder para estabelecer princípios de seleção, de ênfase e de orientação no subcampo JEB - em função dos cuidados nas relações e das crenças compartilhadas que mantêm os vínculos com as fontes, mantêm e reavivam a hierarquia das perspectivas e enquadramentos possíveis sobre a vida econômica e 
financeira da sociedade: observando e publicando, em maior ou menor medida, seletivamente; avaliando e julgando a partir de uns princípios e não de outros; e prescrevendo soluções e remédios.

\section{Características estruturais da elite}

Adotamos uma definição de elite bem simplificada: pertencem à elite aqueles localizados no cimo das instituições (COMBESSIE, 2001). Em linha como Pedroso Neto e Undurraga (2017), são os jornalistas da economia que operam como colunistas, editores-executivos e diretores de redação e edição de jornais especializados - Gazeta Mercantil, Valor Econômico - e dos principais jornais generalistas nacionais - $\mathrm{O}$ Estado de São Paulo, Folha de São Paulo, O Globo, Jornal do Brasil. Os outros, os não elite, atuam como redatores, editores e repórteres especiais (PEDROSO NETO, UNDURRAGA, 2017; no prelo).

Os trabalhos de Pedroso Neto e Undurraga (2017) mostram que há uma forte divisão no espaço do JEB, a partir de princípios como idade, local de origem geográfica e de trabalho, modo de inserção profissional, circulação pelos veículos dominantes e especializados e, em menor proporção, acesso às premiações. E apresentam outra divisão no espaço, baseada em princípios como trajetórias escolar e profissional, origem social e idade. Em síntese: os mais velhos têm origem social mais elevada - maior proporção de pai com ocupação intelectual -, cursaram universidades públicas - ex. Universidade de São Paulo (USP) e universidades federais -, começaram a trabalhar como jornalistas nos anos 1960 e 1970, como jornalistas da economia em agências de notícias - ex. Agência Brasil/Radiobrás, Agência Telenotícia da Revista Visão - ou veículos generalistas maiores, de abrangência nacional - ex. O Estado de São Paulo, Folha de São Paulo, O Globo, Jornal do Brasil, revistas Veja e Isto É - e, na trajetória profissional, em grande medida, trabalharam em todos eles; por outro lado, os mais novos têm origem social mais modesta - maior proporção de pai com escolaridade primária e ocupação manual -, estudaram em faculdades privadas - ex. Pontifícias Universidades Católicas, Cásper Líbero, Metodista, Unisinos, Gama Filho, Fundação Armando Alvares Penteado (FAAP), etc. -, começaram a trabalhar como jornalistas nos anos 1980, como jornalistas da economia em jornais generalistas menores - ex. Jornal da Tarde e Diário da Grande $\mathrm{ABC}$ - e grandes - ex. Correio do Povo e Zero Hora - e não trabalharam em todos os grandes jornais generalistas durante a carreira (PEDROSO NETO, UNDURRAGA, 2017; no prelo). 
Esses autores também revelaram os trunfos e as trajetórias da elite; pioneirismo, especialização e audiência. Isto é, contrastando elite e não elite, apresentam outros dados fundamentais. Primeiro, sobre diferenças geracionais entre elite e não elite, relativas à idade - 50 a 59 anos ou menos versus 60 a 69 anos ou mais -, ao momento de início na atividade de jornalista - anos 1960 versus anos 1980 - e ao momento de conclusão do curso superior - anos 1960 versus anos 1980. Segundo os da elite têm origem social mais elevada e os da não elite mais modesta, como apresentamos acima. O terceiro dado basilar é a sobre o início e a trajetória nos meios. Há uma diferenciação relacionada às características e às dimensões dos meios em que os jornalistas iniciaram a carreira e dos meios em que atuaram durante a carreira; jornal, revista, agência de notícias, rádio e televisão. Ela está organizada a partir de pares de princípios opostos, alinhados à diferença elite e não elite: jornais generalistas versus jornais especialistas; maiores jornais versus menores jornais; maior acesso a audiência - além dos veículos generalistas maiores, o rádio e a televisão - versus menor acesso à audiência; maior audiência e reconhecimento externo versus maior prestígio e reconhecimento interno - os jornais Gazeta Mercantil e Valor Econômico (PEDROSO NETO, UNDURRAGA, 2017; no prelo).

Os autores analisaram também as diferenças internas à elite. Há pouca diferença etária entre eles e se confirmaram os pares de princípios opostos supracitados. Mas revelaram uma divisão a partir de dois princípios; maior audiência e reconhecimento externo versus maior prestígio e reconhecimento interno. Quer dizer, os mais velhos fizeram carreira e estão nos grandes veículos generalistas nacionais e também no rádio e na televisão. E os que são um pouco mais novos fizeram carreira e estão nos veículos especializados, fundamentalmente os jornais Gazeta Mercantil encerrou as atividades em 2009 - e Valor Econômico, ambos amplamente reconhecidos pelos jornalistas da economia como os que encarnam os princípios de excelência do JEB (PEDROSO NETO; UNDURRAGA, 2017; no prelo)

\section{A dinâmica dos jornalistas da economia: mexer com o mercado e ter relações com economistas, dirigentes e empresários do mundo das finanças}

Vamos começar tratando de algo que é amplamente compartilhado pelos agentes do espaço: a noção de furo e a de que, atualmente, o predominante é o de assuntos relacionados às finanças - informações, agentes, instituições, processos. A noção de furo, de exclusividade, de ser o primeiro a publicar sobre um assunto é um móvel importante das ações dos jornalistas, como já foi registrado pela literatura 
(SCHUDSON, 1995; BOURDIEU, 1997b; DUVAL, 2004; NEVEU, 2006; STARKMAN 2014) e como redunda no conjunto das entrevistas. Os agentes da elite reconhecem espontaneamente - sem perguntarmos - que se realizam profissionalmente ao dar um furo: "exclusividade", "dar a notícia de primeira mão", “conseguir a capa", "primeira página", "manchete", etc. Esse princípio é a variante principal da noção mais geral de ter audiência, "ter leitores", "ser a coluna mais lida", "coluna mais divulgada inclusive por jornais concorrentes", "ser a terceira coluna mais lida no impresso".

Essa é uma das dimensões da illusio. O jornalista se sente realizado, ele é reconhecido pelos pares, pelas fontes, pelas possíveis fontes, etc.

Porque coisa melhor de um jornalista é ter um furo na mão. É uma sensação maravilhosa, de uma adrenalina, de uma coisa. Quando uma empresa vai comprar a outra, que tem bilhões envolvido. Essas matérias do jornalismo econômico que vai mexer com o mercado, eu fiz milhares de matérias. [O que você mais gosta do trabalho do jornalismo econômico?] É o furo. É dar o furo; uma coisa que ninguém deu, que ninguém sabe, que vai mexer, principalmente, com esse mercado que eu odeio, que vai mexer com todo mundo. [...] $\mathrm{O}$ dia que eu dei essa manchetinha do jornal, eu recebi ligações do mundo inteiro. De pessoal de analista de mercado. Do mundo inteiro (Elite - Ex-Gazeta Mercantil e Ex-Valor Econômico).

Que tipo de furo é dominante, salvo os extraordinários? Outro princípio estabelecido e operante no espaço do JEB - dinamiza, instiga a atividade do jornalista; a noção de "mexer com o mercado".

A literatura indica que, nos anos 1970 e 1980, no JEB, a realização dessa dimensão da illusio, em parte, era devida a ter boas relações com os ministros do planejamento e da fazenda dos governos militares - "caderno de endereços de autoridades", segundo L. Nassif (LENE, 2013, p.115) - e, em parte, também era devida a ter textos ou colunas de grande audiência - mais lidas - no corpo dos jornais (CALDAS, 2003; PULITI, 2009; LENE, 2013).

Nos dias atuais temos fortes indicadores de que um dos princípios fundamentais que hierarquiza os textos e os autores, levando-os às manchetes, é a ideia geral de "mexer com o mercado", ou seja, produzir matérias mais relacionadas a atividades financeiras de modo geral: das empresas, do governo, do Banco Central do Brasil, da bolsa de valores, etc. Espontaneamente, tanto jornalistas da elite como da não elite reconhecem isso, explicitamente como no exemplo anterior, ou tacitamente como exemplo a seguir: "Não faço nada de economia formal. Dificilmente, a não ser 
quando estou em coberturas fora ou coisas muito quentes eu escrevo no Pro [Valor Pro]. O que eu acho interessante não imediatamente mexe com os mercados. Vai mexer no futuro, mas não imediatamente" (Não elite - Valor Econômico).

Análises mais específicas sobre o jornal Valor Econômico - atualmente o especializado em economia mais importante - demonstram algo próximo de uma institucionalização do empuxo em relação às atividades financeiras. O Valor Pro, um segmento do jornal Valor Econômico, foi lançado em janeiro de 2013 para oferecer notícias em tempo real, focadas no Brasil, nas bolsas de valores nacionais e estrangeiras, nas políticas econômicas e nos processos legislativos que afetam mercados financeiros. O objetivo era competir com veículos semelhantes, como Bloomberg, Reuters, Dow Jones e, principalmente, a Agência Estado - o fornecedor nacional dominante de notícias em tempo real, desde os anos 1990 (UNDURRAGA, 2017a).

Como explica Undurraga (2017a), a entrada em cena do Valor Pro no espaço da redação do Valor Econômico resultou de um aumento da pressão do setor financeiro sobre a produção de notícias. Com o Valor Pro, economistas de bancos e operadores do mercado financeiro tornaram-se os principais informantes, as principais fontes sobre a economia - pela disposição para comentar eventos em tempo real e pelo manejo de informações atualizadas. Na prática, menos acadêmicos, menos representantes de setores comerciais, produtivos e trabalhistas são chamados para comentar os eventos econômicos.

No jornal, a maior dedicação ao mundo das finanças desencadeou uma intensa disputa entre os jornalistas sobre o quantum de atenção que é dada às finanças, em oposição à economia real. As disputas revelaram jornalistas em posições liberais e desenvolvimentistas e com noções normativas diferentes sobre o que significa cobrir bem a economia. Enfim, evidenciaram diferentes ordens de valor que colidem e cooperam na redação do jornal, refletindo diferentes entendimentos da economia, da sociedade e da proficuidade do jornalismo (UNDURRAGA, 2017a, 2017b).

Alguns editores acham positivo dar maior papel e destaque aos mercados financeiros e à agenda liberal de investidores e instituições financeiras. Outros afirmam que a financeirização do jornal foi longe demais e lamentam alguma perda de conexão com a economia real - por exemplo, com indústrias, pequenas e médias empresas, funcionários públicos, realidades do interior do Brasil e público em geral (UNDURRAGA, 2017a, 2017b).

Voltando às nossas entrevistas, temos casos recorrentes de reconhecimento espontâneo de que, ao conseguir algum feito importante - entrevista, informação 
exclusiva, inédita -, o jornalista comemora, relata como uma grande realização e expõe que chamou a atenção e estabeleceu uma relação com os agentes dos mercados.

A crítica a este direcionamento das atividades dos jornalistas da economia, presente no espaço da elite, é crítica e reconhecimento e, não por acaso, vem de agentes que não estão mais nos grandes veículos.

[L. Nassif] A cobertura continua seguindo o 'efeito manada'. Ocorre quando você tem temas complexos, e o jornalista não quer correr risco [...]. O pauteiro pela manhã faz a pauta, passa para o repórter que está em começo de carreira [...]. Ele sai e vai buscar as mesmas fontes que vêm com as mesmas análises. Esse 'efeito manada', na medida em que o Brasil foi se sofisticando, se tornou mais forte ainda. Nos anos 1990, você tinha uma economia sofisticada. Antes, você cobria como? Tinha setorista na Fiesp, um na Febraban, um no Ministério da Fazenda, um no Banco Central. O país se sofistica tremendamente, mas o modo de produção continua o mesmo. $\mathrm{E}$ você tem o advento dessa financeirização da economia e isso muda bastante coisa e você passa a ter o 'efeito manada' de forma total (LENE, 2013, p.433).

Enfim, este elã dirige e impulsiona as atividades e, em função do modo como é reconhecido, afirmamos; o princípio de "mexer com o mercado" é o predominante no subcampo JEB, quer dizer, há outros, mas na hierarquia ele predomina.

\section{As fontes dos jornalistas da economia}

Procurando revelar como se consegue os furos, exploramos o que é reconhecido como sua principal origem; as fontes de informação. De modo geral, podemos esboçar três modos típicos dos jornalistas se relacionarem com suas fontes. Aquele que vamos chamar de mais frio e de menos prestígio; contatos para checar, conferir, apurar, informações, obter explicações e esclarecimentos de fontes de menos prestígio e de assessorias de imprensa. Os relacionamentos com fontes impessoais; com estatísticas, agências de informações financeiras. E os relacionamentos mais quentes e de mais prestígio; contatos que permitem buscar, cavar, garimpar uma informação exclusiva, de bastidor, uma pista, uma entrevista.

As fontes mais frias e impessoais são mais relatadas pelos não elite, mas não exclusivamente. Quando relatam relações com fontes, não nomeiam diretamente as pessoas, mas simplesmente dizem minhas fontes, uma fonte de empresa, uma fonte de mercado, relatam e-mail e telefonema, algo menos tête-à-tête e mais frio, mais 
pulverizado e/ou ligado a colegas do outro lado, isto é, ex-jornalistas que foram trabalhar como assessores de imprensa.

Eu vejo basicamente dois caminhos: tem gente que tem muita fonte, que tem fontes dentro. Para você cobrir bem empresas, você tem que ter fonte em banco. Banco e advogado. Eles que falam mais, dão mais com a língua nos dentes para tirar furo. São as duas fontes de furo. As empresas... Empresário geralmente é muito mais contido. [...] É, então você tem uma fonte na empresa que é um cara que você consegue lidar e ele te dá uma posição, mas você tem que ter vinte, trinta anos de profissão (Não elite - Valor Econômico).

Hoje em dia, então, a gente fala com as fontes que nos dão informações e busca complementar aí com esses consultores, com analistas e com algum especialista, algum estudioso das áreas. [...]. Tem o lado das assessorias, só para completar, que ficam querendo empurrar um monte de coisas para cima da gente. Empurrar notas, empurrar notícias que não tem informação e seria mais marketing para empresa do que notícia mesmo. E essas assessorias é um assédio constante, desgastante; mandam releases, ficam telefonando, sugerem almoços, sugerem encontros com executivos e, geralmente, esse pessoal não tem notícia. É só mesmo para poder emplacar a empresa, colocar a empresa [...]. Tem as assessorias que dificultam o trabalho, tentam barrar informação. Ainda tem muita assessoria que tenta principalmente quando a informação é polemica para a empresa e as assessorias, em geral, tentam fazer com que você não dê a reportagem te oferecendo compensações. [...]. Tipo assim: não, se você não der isso nós vamos depois te dar uma exclusiva com o presidente para falar quando tiver outro negócio (Não elite - Valor Econômico).

Por outro lado, os da elite, quando relatam sobre elas, se referem às dificuldades dos iniciantes que ainda não acumularam ligações profissionais de confiança com boas fontes. Não relatam sobre eles, mas sobre os outros.

Em relação às fontes impessoais, um dado fundamental é a imposição das agências de informações financeiras on-line como o serviço Broadcast da Agência Estado e as semelhantes como Bloomberg, Economática, Reuter e Valor Pro e empresas de consultoria de informações financeiras.

Em 2006, os sócios propuseram de criar um serviço de notícias em tempo real. Quem participa desse mercado: Agência Estado do O Estado de São Paulo. Eles tinham um serviço chamado broadcast desde os anos 1990. [...] Valor acha que pode entrar nesse mercado. [...] A gente tinha Bloomberg, a Bloomberg tirou. Diz 
que agora somos concorrentes. Tiraram, romperam, tiraram o terminal deles daqui. Para a gente era fundamental porque ali a gente não pegava noticia deles, a gente tem até um acordo de publicação de notícias dele, como tem com a [...], com a [...], mas a gente usava o mesmo terminal, mas eles [...], porque se tem notícia tem terminal, terminal banco de dados, tiraram, tá bem complicado pra gente (Elite - Valor Econômico).

E a Bloomberg também cortou. Então, a gente criou um problema porque a gente não tem isso ainda. A Bloomberg é um exagero porque nós nunca vamos competir com eles. Agora, a gente ainda não tem o que a Economática tem. [...]. Sem a Bloomberg, sem Economática e dependendo de um produto que ainda não foi desenvolvido plenamente [...]. É uma ferramenta como tem a Economática que consegue mais amigavelmente possível te dar informações com estabilidade. Você sabe que pode confiar naquilo. E o cara precisa disso, ele quer saber: quero saber como está o dólar agora, a bolsa. Então, são coisas que nem isso a gente tem conseguido fazer (Não elite - Valor Econômico).

Quanto às agências de informações financeiras, trata-se de instituições criadas desde fins dos anos 1980 que auxiliam os jornalistas com dados e informações. Outra fonte de informações são as empresas de consultorias

Eu acho que a gente teve uma mudança muito grande de fonte de informação. 15, 20 anos atrás, você ainda tinha a academia como uma grande fonte de informação. Só que o tempo em que a academia funciona e o tempo em que o jornalismo econômico passou a funcionar também muito em função dessa rotina de tempo real, de site e dessa informação mais rápida. São tempos em que você passou a ter uma necessidade de gerar informação muito mais rápido do que o tempo que a academia de processar. Essa coisa da rapidez com que a informação passou a girar, fez com que você cada vez mais passasse a usar fontes do mercado, do mercado financeiro mesmo ou mesmo de consultorias que não são ligadas aos bancos, mas que vendem informação, que vendem a análise econômica como parte do seu negócio. E aí eles, sim, estão olhando esses dados e produzindo informação com uma rapidez muito grande. Então, essas fontes estão disponíveis para você. Então, eu acho essa uma grande mudança. E o impacto dessa mudança é que você acaba tendo a visão econômica do mercado e a visão econômica mesmo dessas consultorias que ela acaba... Você está procurando eles e eles têm a sua visão sobre tudo isso e essa visão acaba contaminando a própria leitura no jornalismo econômico (Não elite - Valor Econômico). 
Não pudemos analisar mais detalhadamente as relações dos jornalistas com essas fontes de informação. Pelo que pudemos depreender, elas são acessíveis a todos de uma editoria. Ficou um pouco saliente nas entrevistas que os da elite conseguem usar o acesso a essas informações ao mesmo tempo que publicam suas matérias nos mesmos meios e, com isso, conseguem obter repostas ou contatos de agentes importantes do campo econômico e do governo. Mas, enfim, essa prática precisa ser melhor explorada.

As fontes de prestígio, como mencionamos, contatos mais quentes, de mais prestígio e pessoais. Quando a elite relata um furo ou algum feito importante que "dá uma capa", ela relata relações com fontes que nomeia e que são pessoas de prestígio porque passaram por governos, são proprietárias-sócias de empresas, consultorias, bancos, instituições do espaço das finanças.

Por exemplo, Edmar Bacha eu conhecia muito antes, era meu amigo. Tivemos um acordo, seguinte: enquanto você estiver no governo não somos mais amigos. Você é fonte de informação e eu sou jornalista porque eu não quero que amigo me peça as coisas e diga: [nome da jornalista], você pode publicar isso. [...] Quando o Arminio Fraga me liga e me diz que quer me dar uma entrevista é que ele tem confiança no meu trabalho. E eu tenho confiança nele como fonte de informação. Mas é uma entrevista porque eu pergunto e ele responde. E eu pergunto coisas que ele não gostaria de responder. [...] Vou te dar um exemplo. $\mathrm{Na}$ véspera da eleição do FHC, que era o segundo mandato, um diretor do banco central, Francisco Lopes, me deu uma entrevista [...]. Quando eu cheguei, ele disse assim: [nome da jornalista], deixa eu botar as minhas ideias em ordem, faz uma coisa você é técnica de entrevistas. Eu disse: faz uma coisa, vai falando. Porque quando ele fala isso, "colocando minhas ideias em ordem", ele quer falar alguma coisa. Eu disse: vai falando e eu vou gravando, não vou perguntar nada, as perguntas eu vou fazer depois, vou anotar e faço depois. Essa criatura que desancou, desancou. Com o Malan, estavam no auge negociando o acordo com o FMI. O Ministro da Fazenda e o Presidente do Banco Central estavam lá negociando acordo com o FMI [...]. Quando ele acabou de falar, eu falei: eu tenho uma manchete do jornal na mão. E aí perguntei pra ele uma coisa que, para mim, interessa ao leitor: o déficit público estava alto, então o que o governo faria para, o que você está planejando para diminuir o déficit? Ele virou pra mim e disse assim; só aumentar os impostos. Então, é contra os interesses do governo, mas quem estava falando isso é o Diretor do Banco Central, a partir de uma pergunta minha, evidente. Então, o leitor quer saber, havia desconfiança que o governo poderia aumentar os impostos. Então, eu fiz a pergunta, é isso. Do ponto de vista de leitor, não interessa para o leitor que os impostos estejam 
aumentando. [mas, uma pergunta, quem é o leitor?] A população. Aliás, quem é o leitor? [...] Você tem razão quando você diz; quem é esse leitor? Esse leitor é o mercado financeiro, é a indústria, são os industriais, são os economistas, são os sindicatos de trabalhadores, são os sindicatos patronais (Elite - O Estado de São Paulo).

A prática dessas relações é do âmbito das relações individuais de cada jornalista, e também é institucionalizada por um jornal.

O imediato para mim é a manchete dessa manhã do jornal, é a Petrobras. [...] Veio aqui tomar um café da manhã com a gente o segundo homem do Ministério da Fazenda, que já saiu da Fazenda. Era o segundo homem do Mantega, o [...]. Ele veio na semana passada tomar um café com a diretoria, eu estava junto, eu participo desses cafés. Ele já saiu do governo, mas é um consultor importante e ele falou em off, não deu entrevista. Mas ele falou várias coisas importantes. Falou sobre o superávit primário, sobre nossa questão fiscal, que é gravíssima. No meio disso tudo, nós perguntamos para ele por que o Brasil não cresce, o Brasil não cresceu nada em 2013. Ele virou para nós e disse o seguinte: o Brasil não cresceu nada por vários motivos, mas também não cresceu porque a Petrobras e a Vale tiveram problemas. Aí todo mundo falou: a Petrobras teve problema porque não reajustou os combustíveis, é verdade? Ele falou: a Vale teve problema porque no mundo, no setor mineral, que é onde a Vale trabalha, quatro presidentes das quatro maiores empresas minerais do mundo foram trocados. [...] Pois bem. Sentei com o [nome de jornalista], conversei um pouco com ele e falei: a Petrobras não reajustou e o [...] falou que ela é $10 \%$ dos investimentos do país. E, como ela não reajustou os combustíveis, ela não investiu. Isso foi um problema. Aí veio a menina que está em Brasil agora, a [nome de jornalista], conversou com a repórter dela; um se juntou com o outro, todo mundo se juntou, usaram repórteres para trabalhar e eles fizeram duas páginas de Petrobras na editoria de Brasil. Saiu na manchete de hoje. O que é a manchete de hoje? É uma matéria que ninguém tem na imprensa brasileira hoje. É um retrato da maior empresa do Brasil, que é uma das maiores do mundo, que é a Petrobras. A matéria hoje, não é uma matéria sobre petróleo, é sobre a economia brasileira. É o seguinte: está dizendo resumidamente para o leitor que o governo brasileiro, para cuidar da inflação e deixá-la menor, não reajustou os combustíveis. Ao não os reajustar, ele impediu que a economia brasileira crescesse. [...] Em um parágrafo você contou a história da manchete. Eu estava acompanhando essa matéria a ser confeccionada. Eu te confesso que eu fiquei felicíssima quando eu fui embora na sexta-feira. Eu tive vontade de chorar quando ao ver a matéria (Elite - Valor Econômico). 
Quando observamos as instituições listadas pelos da elite - os entrevistados, as entrevistas recordadas, os economistas admirados, "brilhantes", "gênios" e/ou "grandes mestres" -, observamos uma relação estreita dos jornalistas da economia da elite com agentes de uma região de interseção entre o campo dos economistas e o campo econômico brasileiros. Região que podermos chamar de espaço dos especializados em finanças e na perspectiva mainstream da economia. Vamos chamar de espaço finanças esse espaço de interseção em que, em maior ou menor medida, agentes atuam a partir dos sentidos, das propriedades ativas de dois campos. Desde o início desta seção, e no decorrer dela, fica claro que há este espaço constituído por instituições, agentes individuais e coletivos, trajetórias profissionais - mais claras a seguir -, disposições, orientações e práticas singulares e compartilhadas que, a nosso ver, estão próximas da dinâmica de um campo social (BOURDIEU, 1997a, 2000).

Os citados têm algumas características de formação acadêmica e de carreira que são semelhantes, são compartilhadas, em maior ou menor medida: primeiro, no campo acadêmico, têm ligações com a Pontifícia Universidade Católica (PUC-RJ) e a Fundação Getúlio Vargas (FGV-RJ) como professores e pesquisadores; segundo, na trajetória profissional, passaram pelo campo burocrático, pelo governo federal em secretarias, ministérios, diretorias, banco central, etc.; e, finalmente, continuando a trajetória profissional, migraram para o campo econômico como consultores, banqueiros, administradores de fundos, proprietários e sócios, mas também presidentes, diretores e analistas, de bancos, empresas de consultoria - monitoramento, análises, projeções, fusões, etc. econômicas, financeiras, políticas, jurídicas - e empresas de investimentos. Puliti (2009) fez um apanhado das três fases da trajetória desses agentes e um de nossos entrevistados se refere a eles espontaneamente quando instado a falar sobre suas fontes.

Pedro Malan, ex-ministro da Fazenda e Unibanco; Mailson da Nóbrega, exministro da Fazenda e sócio-fundador da Tendências Consultoria Integrada; Gustavo Loyola, ex-presidente do BC e sócio-fundador da Tendências Consultoria Integrada; Marcos Lisboa, ex-secretário de Política Econômica do Ministério da Fazenda e Unibanco; Armínio Fraga, ex-presidente do BC, era do mercado financeiro antes de assumir o cargo e quando saiu foi dirigir a Gávea Investimento; Gustavo Franco, ex-presidente do BC e sócio-fundador da Rio Bravo; Carlos Kawall, ex-diretor do BC, também era do mercado financeiro e tornou-se sócio de Gustavo Franco na Rio Bravo; Luiz Fernando Figueiredo, exdiretor do BC e Mauá Investimentos; Ilan Goldfajn, ex-diretor do BC e Ciano Investimento; Sérgio Werlang, ex-diretor do BC e Itaú; Alexandre Schwartsman, 
ex-diretor do BC, era do mercado, foi para o $\mathrm{BC}$ e depois analista-chefe do $\mathrm{ABN}$ Amro/Santander; Eduardo Loyo, ex-diretor do BC e UBS/Pactual; Joel Bogdanski, ex-BC e Itaú; Marcelo Kfouri, ex-BC e Citibank; Carlos Geraldo Langoni, ex-presidente do BC e Projeta Consultoria; Affonso Celso Pastore, exBC e consultoria A. C. Pastore; Luiz Carlos Mendonça de Barros, ex-ministro das Comunicações e dono da empresa de investimentos Quest; José Roberto Mendonça de Barros, ex-secretário de Política Econômica e dono da consultoria MB Associados; Sérgio Goldenstein, ex-BC e ARX Capital Management; Beny Parnes, ex-BC e BBDM; Henrique Meirelles, presidente do Banco Central desde 2003, foi presidente do BankBoston (PULITI, 2009, p.69-70).

Eu converso semanalmente com vários economistas, inclusive com aqueles que não concordo. Na semana passada, almocei com Jose Francisco Lima Gonçalves que é o economista-chefe do Banco Fator. Aqui [no Brasil] temos economistas monetaristas e desenvolvimentistas, keynesianos e neoliberais. Esse debate no Brasil não é um debate saudável. Você não debate ideias, mas posição política; apoia ou não o governo, apoia ou não uma política de Dilma. Eu converso muito: com Mario Mesquita, ex-diretor do Banco Central e hoje presidente de um banco do investimento; com Mário Torós, ex-diretor do Banco Central; com Rodrigo Azevedo que, com o Torós, são sócios de uma empresa de investimento; com Fabio Giambiagi, do BNDES; com José Julio Senna, pesquisador da FGV, sócio da MSM, uma empresa de consultoria renomada, coordenador do Centro de Estudos Monetários, primeiro think tank. Senna escreveu um livro sobre a história da política monetária do mundo [Política Monetária: Ideias, Experiências e Evolução]. Converso também com Alexandre Schwartsman, articulista do Valor e da Folha de São Paulo, foi diretor do Banco Central. Com Monica de Bolle da Galanto, uma empresa do Rio. Também leio bastante Affonso Celso Pastore. Ele foi presidente do Banco Central em fins da ditadura. É um dos meus economistas prediletos. É consultor independente e vende para bancos suas análises econômicas. Ele tem a tese de que quando a taxa de câmbio aparecia no Brasil as empresas aumentavam as taxas de investimento. Coisa curiosa. Exatamente o oposto do que dizem os economistas desenvolvimentistas. Converso com economistas do governo como [inaudível], desenvolvimentista. Converso muito com Alexandre Tombini, atual presidente do Banco Central. Luciano Coutinho, presidente de BNDES, desenvolvimentista. Ambos vêm manhã. Converso com André Lara Resende, Pérsio Arida, Eduardo Azevedo, Armínio Fraga. Tem outros que intercambio e-mails, mas esses são os economistas que eu leio e converso, principalmente (Elite - Valor Econômico). 
Temos aqui um conjunto de empresas financeiras e agentes sociais que, em grande medida, atuam em uma determinada região do campo econômico, a região das finanças. E, do mesmo modo, atuam em uma região do campo dos economistas brasileiros que já foi caracterizada como a do polo dos monetaristas e ortodoxos, ou da economia mainstream (LOUREIRO, 1997).

Outro traço das ligações da elite com suas fontes é que dão um salto institucional; de ter fonte para ter e ser fonte. Isto é, passam a ser fonte de informações, relacionamentos e consultas para Ministros e Ex-Ministros de Estado, Diretores e Ex-Diretores do Banco Central, além de presidentes, economistas, diretores, etc. de instituições financeiras - corretoras, bancos, etc. Isso é um diferencial que mantém e fortalece as ligações com os agentes do espaço finanças. Isso melhora as chances de ser distinto; convite para um café da manhã, uma oferta de entrevista, um furo, uma entrevista exclusiva, etc. Em grande medida, os jornalistas entram em uma relação de reciprocidade com agentes do espaço finanças.

Nós temos contatos diferentes. Eu não tenho contato no Banco Central para isso. Mas, por exemplo, os economistas dos bancos têm reuniões frequentes com o governo. Eles tiveram na sexta-feira, têm hoje. O tempo todo eles estão com o governo. Por exemplo, há dez dias um economista da [...] que fica em Nova York, brasileiro, mas está em Nova York há muitos anos, ligou na minha casa de manhã, em um sábado de manhã, estava no Brasil, tinha vindo na sexta-feira de noite de Brasília. Ele estava aqui em São Paulo e falou: "Olha, estou aqui, você não quer tomar um café comigo de manhã?" Eu falei: "Vou tomar banho e vou." Aí ele me contou tudo o que tinha acontecido na reunião que ele foi no Banco Central e no Ministério da Fazenda. Eu, inclusive, fiz uma matéria com ele. Ele até podia falar, falou muita coisa que ele não podia me falar, em off. Ele me deu várias declarações em on. Mas eles contam absolutamente tudo. Então, depende do grau de confiança que eles têm em você. Tem muitas coisas que eu sei aos pedaços, mas eu também relato. Como eles relatam pedaços, nós conseguimos fechar as pontas. E nós chegamos a um quadro. E este quadro normalmente é escrito. Nós o escrevemos e aí o governo se manifesta. Vem um diretor e liga para mim: você escreveu uma coisa, mas não é bem assim, [nome de jornalista], está falando uma coisa, isso eu contei, mas isso não é explicação. Aí a gente reescreve com a outra explicação. Na verdade, é como se fosse um lego (Elite Valor Econômico).

Tem uma troca. Eu sou muito demandado. Eu e [jornalista] que é a nossa diretora em Brasília. Como a gente acompanha muito de perto o governo e eu, um pouco o mercado e a mesa digital com esse projeto do Valor Pro, eles demandam muito 
da gente. Eu não sou procurado pelos economistas para dizerem esta é minha agenda. Eles procuram para ver para onde vai o governo: o que você acha que o Tombini vai fazer na próxima reunião do COPOM, você acha que a Dilma vai fazer intervenção na economia? [...] Então, os economistas não me chamam para instalar sua agenda, mais para saber os bastidores. Eles querem saber um pouco mais do que está nos jornais. A gente sabe algumas coisas que não publica no jornal (Elite - Valor Econômico).

Devemos ter em conta que há relações diferenciadas que, em grande medida, os jornalistas da elite estabelecem com os economistas. De modo recorrente, há o uso diferenciado das etiquetas profissionais em relação a eles. Nas entrevistas não se faz relatos negativos à pessoa ou à formação acadêmica e se mobiliza princípios profissionais para explicar as relações, tais como ter estabelecido uma relação de confiança, respeito. Em relação aos economistas do polo mainstream do campo dos economistas, essas etiquetas estão presentes. Mas são deixadas de lado quando se referem àqueles do polo oposto; os "economistas da Unicamp" - Instituto de Economia da Unicamp ${ }^{2}$.

Há uma ligação forte da elite do JEB com agentes do espaço finanças. A manutenção dessas relações tem implicações para o conteúdo e as pautas dos jornais. Elas são expressas e vividas como tensões entre o dever e a ética profissional em manter a integridade da pessoa, a credibilidade do jornalista e do jornal. Na prática, elas são vividas com uma deferência dos jornalistas aos agentes do espaço finanças e isso fica visível quando se compara o modo como usam a etiqueta, como apresentaremos mais adiante.

No Brasil, as estruturas do campo dos economistas se atualizaram e firmaram a partir dos anos 1970, com a renovação e a modernização dos cursos de economia currículo, origem social dos alunos e professores -, a formação da pós-graduação, o aumento do número de alunos nos dois níveis, a formação no exterior de jovens professores, especialmente nos EUA, a criação de periódicos acadêmicos, o aumento expressivo do número de artigos publicados e a ascensão dos economistas - muitos professores desses cursos formados no exterior - aos postos de elite no Estado (LOUREIRO, 1997, p.61-70).

\footnotetext{
2 Uma questão pode ser desdobrada: quais são as dimensões das relações sociais, do capital social, dos jornalistas e como eles as construíram e acumularam? Podemos ter a importância, o peso relativo, do capital social na dinâmica dos jornalistas - ascender na carreira, acessar e estabelecer fontes, mudar de carreira, etc. - como um ponto pacífico, dada sua presença na literatura específica sobre o JEB. Mas uma sistematização mais geral sobre o peso relativo dos tipos de relações sociais - profissionais, parentesco, amizade, política, etc. - e de como foram estabelecidas e reproduzidas ainda precisa ser feita.
} 
O estado do campo dos economistas brasileiros, estabelecido a partir dos anos 1970, reforçou a polarização existente no estado anterior; cepalinos estruturalistas heterodoxos versus autodidatas monetaristas ortodoxos. Atualmente, a polarização se revela a partir de um conjunto de pares de opostos que estruturam as lutas e diferenciações internas: PUC-RJ e Escola Brasileira de Economia e Finanças (EPGE/FGV-RJ) versus Universidade Federal do Rio de Janeiro (UFRJ) e Instituto de Economia da Unicamp - Faculdade de Economia, Administração e Contabilidade da Universidade de São Paulo (FEA/USP) e FGV-SP no meio; modelização matemática e econometria versus abordagem histórica, institucional, social e política dos processos; internacionalização versus menos internacionalização; modelo de ciência hard nos moldes das ciências extas versus modelo de ciência soft nos moldes de domínio de obras e autores clássicas; uso de literatura predominante em inglês versus uso predominante em português; textos de referência mais novos versus textos mais antigos; Revista Brasileira de Economia e revista Pesquisa e Planejamento Econômico versus Revista de Economia Política - a revista Estudos Econômicos da FEA/USP é mista; estratégias de carreira junto ao FMI, Banco Mundial, consultorias, bancos privados versus universidades públicas, agências governamentais, empresas públicas (LOUREIRO, 1997, p.70-84).

Figuras públicas como empresários, ex-ministros, economistas são citados recorrentemente nas entrevistas com os da elite, como vimos. Eles aparecem como boas fontes e pessoas admiráveis; entrevista que dá "uma capa", economistas "brilhantes", "gênios", etc. Quando observamos essas figuras, vemos que elas são da região FGV-RJ e PUC-RIO do campo dos economistas. Em relação a elas são mobilizados princípios do mundo profissional que, conforme argumentam, resultam em respeito e confiança; representante do leitor, ética, respeito, etc. Mas há uma diferença na forma de se referir aos ex-ministros, economistas, ideias, ideologias, representações, saberes do outro polo do campo dos economistas brasileiros. Em relação a esses agentes e representações as críticas e avaliações negativas são explicitadas.

E coloca o Mantega, que é um merda. Ele é um zero à esquerda. Ninguém respeita o Mantega. Ele não tem presença nem tem cabedal intelectual. Então, ele é mandado por Dilma [e continua...]. Derivou para o Plano Real, quando veio uma cabeça keynesiana, com pessoas muito capazes; Pérsio Arida, André Lara Resende, também havia o Edmar Bacha. Ali eu passei a compreender: é isso mesmo, você tem de abrir o país, tem que haver um choque de competição (Elite $-\mathrm{O}$ Globo). 
Então, isso; seria bom o seguinte, avaliar a qualidade de uma análise feita pela Unicamp, pela PUC, pela FGV, pela UFRJ, pelos economistas que preferem as 4, avaliar a qualidade da análise econômica feita por esses economistas. [qual é sua impressão aí?] Eu não conheço muito bem a impressão de quem eles chamam de campineiros. Campineiros é o pessoal de Campinas, mas alguns deles são... muito ideológicos, voltados para um passado. Eu também fui partidária, fui presa, meu marido foi preso porque éramos ligados ao socialismo, mas o que era o socialismo? [...] Então, mas alguns de campinas não são todos. [...]. É diferente porque eu acho que a análise mais inteligente deve ser do pessoal da PUC (Elite - O Estado de São Paulo).

Novamente, temos em conta que o espaço da elite não é monolítico, pois há posições dissonantes. A crítica dos jornalistas dissonantes, ou as disputas entre os próprios jornalistas, revelam não só a diferença entre eles, mas também o reconhecimento da importância dos agentes do espaço finanças.

[L. Nassif]. Desde o início, André Lara Resende era defensor intransigente da remonetarização com poupança externa. Na gestão de FHC na Fazenda, André concordou em completar o processo de renegociação da dívida externa. Ali, ampliou contatos com banqueiros internacionais. Com a rede de contatos externos ampliada por sua posição de negociador da dívida, saiu do governo para operar no mercado. Mas continuou tendo participação ativa nas formulações econômicas, em um caso flagrante de insider information. Aliás, era mais do que o insider. Era o economista com dupla militância, ajudando a definir as regras do Real e, depois, operando no mercado em cima dessas mesmas regras (LENE, 2013, p.432).

Temos várias formas de ligação dos jornalistas com as fontes ou com os agentes do espaço finanças ${ }^{3}$. Elas implicam em vínculos de confiança e reciprocidade. Podemos pensar em um leque dos possíveis que ocorrem, de fato: de um lado, as

\footnotetext{
${ }^{3}$ Uma questão pode ser colocada: qual é o grau de autonomia dos jornalistas da economia, subcampo JEB, vis-à-vis os economistas, campo dos economistas brasileiros? Esta pesquisa não a resolve sistematicamente, mas indica uma direção de autonomia restrita, como procuramos apresentar nesta seção e na subsequente do texto. Alguns trabalhos mais sistemáticos indicam a mesma direção, isto é, trabalhos que pesquisaram a questão comparando os enquadramentos presentes em matérias jornalísticas e os presentes em artigos de economistas na imprensa, quando trataram do mesmo assunto; a reforma da previdência social (SOUZA, 2019), as ações e funções do Banco Nacional de Desenvolvimento Econômico e Social, BNDEs (ROSA, 2019; ROSA, PEDROSO NETO, 2019) e a política fiscal de desoneração do Imposto sobre Produto Industrializado, IPI (VELOSO, 2018).
} 
relações que contribuem para a construção da notícia no dia a dia, as matérias mais rotineiras, para as quais são mobilizados os contatos mais frios, de menos prestígio e impessoais; de outro lado, as relações que contribuem para construção de matérias mais destacadas - colunas, entrevistas, "manchetes", "capas" - para as quais são mobilizados os contatos mais quentes, de mais prestígio e pessoais. São essas matérias que, em maior medida, realizam a illusio da profissão, que permitem estabelecer e reestabelecer posições centrais no subcampo JEB. Isto é, posições com poder de agendar temas e enquadramentos, de consagrar princípios de excelência, de admiração, de reconhecimento - por exemplo, jornalistas, colunistas, diretores como Miriam Leitão, Suely Caldas, José Kupfer, Carlos Sardenberg, Angela Bittencourt, Claudia Safatle, Cristiano Romero, Luis Nassif, Vera Brandimarte, Vera Durão, dentre outros.

A manutenção dessas relações tem implicações para o conteúdo e as pautas dos jornais. Elas são expressas e vividas como tensões entre o dever e a ética profissional em manter a integridade da pessoa, a credibilidade do jornalista e do jornal. Devemos considerar que, em função da necessidade dessa teia de relações, os jornalistas têm relações objetivamente necessárias com os agentes e as representações do espaço finanças. Com essa teia, eles mantêm o acesso a fontes privilegiadas e, assim, os benefícios resultantes, como a realização das dimensões da illusio singular do espaço do JEB. Mas não é só isso. Devemos considerar também que a apresentação espontânea dessa postura ética e profissional expressa uma denegação (BOURDIEU, 2007) da submissão a uma teia de ligações necessárias e esconde certa submissão à doxa do espaço finanças ao mesmo tempo que uma sensata adesão implícita ou explícita a essa doxa, por conta da formação dos jornalistas em economia.

\section{Formação autodidata e sob ascendência da região FGV/PUC-RJ}

Ao explorarmos a entrada e a formação dos jornalistas na especialidade economia, encontramos relações no processo de aprendizagem que indicam certa ascendência dos agentes do espaço finanças sobre eles. Os jornalistas, de modo geral, não aprenderam economia no curso superior em jornalismo e iniciaram no jornalismo econômico mais por acaso do que por formação específica, como é recorrente nas entrevistas: "Comecei em 1970, no Jornal do Brasil, [...] e, não é que eu quisesse ser jornalista econômico. Fui designado para Editoria da Economia, gostei e me quedei lá. [...] Então, eu me formei, e foi uma coisa muito boa, lendo muitos relatórios de Bancos Centrais e discussões, etc". (Elite - O Globo). 
Eles aprenderam economia nas ações práticas como jornalistas: nas redações Gazeta Mercantil foi a "grande escola" -, nas entrevistas com economistas, com "grandes economistas", com diretores e especialistas de bancos, com ministros, nas pesquisas por dados e informações, nas assessorias de imprensa de instituições, etc., E, mais recentemente, em especializações universitárias quando já atuam como jornalistas. Isso é recorrente no conjunto das entrevistas e já foi registrado pela literatura (ABREU, 2003; RESENDE, 2005; RIBEIRO, PASCHOAL, 2005; ABREU, ROCHA, 2006; PULITI, 2009; LENE, 2013; PEDROSO NETO, 2015).

Duas formas são mais recorrentes entre os entrevistados da elite, e não são entre os não elite: além da "grande escola Gazeta Mercantil" relatam o aprendizado nos órgãos governamentais do espaço da finança e com agentes do espaço finanças.

A primeira forma é relatada por jornalistas da economia da elite que foram assessores de imprensa em secretarias, ministérios e bancos governamentais:

[Como o senhor começou no jornalismo?] [C. A. Sardenberg] Não foi bem por acaso. Foi por uma circunstância política. Estava estudando na faculdade, fazia curso de direito e filosofia. [...] E teve aqueles acontecimentos de 68/69. O AI-5 em 1968. A ditadura ficou mais forte. [...] Para resumir eu não podia ir mais na faculdade. $\mathrm{O}$ resultado foi que não pude pegar meu diploma de filosofia e também não podia dar aula no cursinho, então fiquei sem emprego e sem carreira. Foi nesse momento que um amigo do meu pai que era jornalista na "Veja" [revista], falou: "estão precisando de gente no Estadão". Daí eu fui pro "Estadão". [...] Eu comecei no jornalismo econômico depois de 1985, quando saí do governo. Por acaso fui trabalhar na Secretaria da Fazenda no Ministério do Planejamento, e aí eu desenvolvi esse conhecimento em economia. Eu tinha de escrever os documentos do Ministério da Fazenda e do Ministério do Planejamento sobre reforma econômica. Quando chegou mais ou menos 1982, o MDB [PMDB] ganhou a eleição para governador em todo o país. [...] Começou dentro das oposições um debate muito grande sobre políticas econômicas. [...] Acabei me envolvendo com um grupo que ficava em torno da Secretaria da Fazenda, João Saiad [ministro do Planejamento na gestão de José Sarney] e vários outros economistas. Um dos meus papéis era redigir os textos. Era difícil porque tinha de falar de inflação inercial, correção monetária, reforma monetária, troca de moeda, apresentar isso para Ulisses Guimarães, Fernando Henrique (MATOS, 2008).

Veja só, na crise de 2008, quando eu estava no Banco Central, foi um aprendizado fenomenal. Olha o desafio: o Lehman quebra. O Brasil estava no seu melhor momento. [...] Aí quebra aquele banco. Aí você tem toda a imprensa brasileira para explicar o que era uma crise que você não estava vivendo. Aí você 
tem que estudar aquela crise. Aí nós estudamos a crise com os diretores do banco, que são grandes economistas. Todos estudaram fora do país, todo mundo é doutor. Aí estudamos a crise para contar o que estava acontecendo lá. [...] Você tinha que fazer operações para poder explicar como você solucionaria uma questão. Eram coisas tão complexas. São operações muito complexas de socorro, de tirar dinheiro de reserva, de fazer leilão de dólar. São coisas que o Brasil não fazia. O Brasil nem tinha reserva antigamente. Hoje em dia o Brasil constituiu grandes reservas. E você manusear aquilo, fazer aquilo. [...] A coordenadoria geral do banco me deu a missão de fazer os dossiês das intervenções de todos os Bancos Centrais do mundo. [...] Nós éramos uma assessoria de doze pessoas, mas tinha o núcleo do presidente. [...] Um deles depois, não sei se você conheceu o [nome de jornalista]? Ele é nosso colega aqui, ele é colunista. [...] Ele foi o primeiro assessor. Ele foi assessor do Meireles, eu saí do banco e ele ainda continuou (Elite - Valor Econômico).

$\mathrm{Na}$ segunda forma, relatam que recorreram aos agentes do espaço finanças, como o exemplo emblemático da jornalista Mirian Leitão.

[A entrevistadora perguntou] Você fez algum curso, alguma especialização em economia? [M. Leitão] Nunca fiz nenhum curso, mas a quantidade de economistas que entrevistei, pedindo "me explica isso, me explica aquilo", equivale a um curso. Passei horas com os principais economistas do Rio, conversando sobre os mais diversos temas. Quando achava que o que eu não entendia ia estourar, perguntava: “como é isso?" Por exemplo, quando a inflação começou a subir cheguei na PUC e perguntei: "quem entende de hiperinflação aqui?" Disseram: “Gustavo Franco". Estacionei no Gustavo Franco: "me explica, como foi a inflação alemã, a húngara, como é a lógica da hiperinflação, como se sai da inflação?" Quando assumi como editora de economia do JB [Jornal do Brasil], o editor executivo do jornal, Flávio Pinheiro, achou, por bons motivos, que eu precisava saber mais sobre economia - e não apenas eu. Fez então um contrato com dois brilhantes economistas da PUC, Rogério Werneck e Dionísio Dias Carneiro, para eles almoçarem comigo uma vez por semana para tirar as nossas dúvidas e nos alertar sobre novos fatos. Foram reuniões magníficas, nas quais aprendi muito (ABREU, ROCHA, 2006, p. 86).

E, novamente, os relatos nas entrevistas indicam fortemente que temos algumas situações típicas que remetem ao momento dos planos econômicos dos anos 1980 e 1990, desde o Plano Cruzado (1986) até o Plano Real (1994). Os jornalistas da elite destacam que tiveram que estudar e que foi o "grande teste para os editores". 
Mas surgiu a possibilidade de trabalhar na Agência Brasil, que foi parte da EBC. Em 1990 eu cobria cidades. [...] Surgiu a possibilidade de cobrir temas nacionais e a economia. Eu fiz uns testes e passei. Naquele momento o Brasil vivia uma instabilidade absoluta na economia. Em 1990, assumiu o primeiro presidente eleito, Collor de Melo. Acabava de lançar o plano Collor, que foi terrível, confiscou os depósitos das pessoas. Então, eu entrei justamente ali. E o Ministério da Fazenda era uma coisa muito intensa. [...] O Plano Collor rapidamente fracassou e logo foi lançado o Plano Collor 2, que também fracassou rapidamente. E começou a preparar o que logo foi o Plano Real. [...]. Quando a economia foi se normalizando, especialmente a partir do Plano Real em 1994, as equipes foram diminuindo. [...]. Eu saí da Agência Brasil e fui trabalhar no Jornal do Brasil. [...]. Foi o grande jornal do país entre 1960 e 1980. [...] Ali eu consolidei uma carreira de repórter econômico. Eu cobri completamente toda a formulação do Plano Real (Elite - Valor Econômico).

Enfim, nessas trajetórias que perpassaram o espaço finanças se formaram ou reconverteram disposições sobre a economia. Dois aspectos se depreendem. Enquanto redundam referências de socialização com a economia, com os agentes, instituições e processos típicos do espaço finanças, não aparecem referências ao polo oposto do campo dos economistas. Outro aspecto complementar é que essas disposições e socializações têm implicações positivas sobre as chances nas carreiras. As chances se devem ao domínio prático de saberes e princípios de visão e divisão de mundo, juntamente com as relações que, além de prestigiosas, permitem dar uma espécie de salto institucional; de fato, são recorrentes as trajetórias de ascensão mais acelerada na carreira.

\section{Considerações finais}

Algumas conclusões são de que os jornalistas que se mantêm na carreira e na especialização têm alguns incentivos e passam por alguns constrangimentos rumo às posições de elite. Estruturalmente, os dados indicam que têm que partir para os grandes jornais generalistas e para o rádio e a televisão, além de aproveitar o capital simbólico acumulado e o acesso ao grande público consumidor, e reconverter na produção de outros bens simbólicos como livros e, principalmente, palestras. Ou podem partir para os jornais especializados, ou melhor, nos dias atuais, para o jornal Valor Econômico. 
Se, há algum tempo - anos 1970 e 1980 -, os jornalistas tinham que ter contatos e fontes no governo federal, as indicações são que, atualmente, têm que ampliar o leque para os agentes, instituições e produtos do espaço finanças. $\mathrm{Na}$ trajetória, nos tempos atuais, têm que ter algum tipo de especialização em finanças e demais princípios de visão e divisão de mundo relativos à economia mainstream.

Isso quer dizer que os jornalistas da economia da elite têm fortes incentivos para realizar a illusio profissional quando têm relações ou compartilham princípios de visão de mundo sobre a economia que são os mesmos dos agentes dominantes no mundo econômico.

Uma das consequências disso é que, esses agentes dominantes, também elites em seus respectivos campos, conseguem espaços nobres - voz e visibilidade - na imprensa de economia e, em grande medida, implícita ou explicitamente, são tratados com deferência, em forma de respeito e ética profissional. As relações têm elementos de tensão, têm contradições, mas não deixam de ser assimétrica e não deixam de reproduzir as tomadas de posição dos dominantes no mundo econômico.

Enfim, algumas pontas da elite do JEB se ligam fortemente com as elites do espaço finanças. A manutenção dessa rede de ligações e a realização da illusio pressupõem um conjunto de crenças compartilhadas - acima das divergências corriqueiras - uma doxa sobre o funcionamento da economia.

\section{Agradecimentos}

As pesquisas receberam apoio: do Conselho Nacional de Desenvolvimento Científico e Tecnológico (CNPq), Brasil; do European Research Council sob European Union's Seventh Framework Programme [(FP7/2007-2013)/ERC Grant Agreement No. 283754 dirigido por Dr. Tiago Mata; do Proyecto Fondecyt 1180611 financiado pela Comisión Nacional de Investigación Científica y Tecnológica (CONICYT), Chile; do proyecto CONICYT PIA Anillo SOC 180039; e de jornalistas entrevistados e que responderam aos questionários. Agradecemos a todos os apoiadores.

\section{ECONOMIC JOURNALISTS AND MEN OF FINANCE: FASCINATION, ASCENDANCY AND PROFESSIONAL ILLUSION}

ABSTRACT: This article explores the impact that agents from the economic field and mainstream economists have on journalists' perspectives on the economy. From the analysis of more than 58 interviews with economic journalists from Brazil, we reveal 
Jornalistas da economia e homens das finanças: fascinação, ascendência e ilusão profissional

how the main opinion makers' positions affect journalists' vision on the economy. Elaborating on Pierre Bourdieu's notion of illusion, we explore their involvement in their work: commitment from the notion of news coup; the means and sources to achieve more important covers; and shape journalists prospects of the economy. Among the results we find the idea of "moving the market" hierarchizes texts and authors. The most prestigious sources in reporting the economy have passed through governments, financial institutions and come from the financial field. Journalists acknowledge reciprocal relations with these prestigious sources, accessing to news coups and special interviews; realizing the illusion of the profession and accessing to key positions in economic journalism. The modes of learning and specialization in economics show the influence of these financial agents in the economic coverage.

KEYWORDS: Economic journalism. Elites. Illusio. Economists. Finance.

\section{Periodistas eCONÓmicos y hOMBRES DE FINANZAS: FASCINACIÓN, ASCENDENCIA E ILUSIÓN PROFESIONAL}

RESUMEN: Este artículo explora el impacto que tienen los agentes del campo económico y los economistas mainstream en las perspectivas sobre la economía de los periodistas. Basado en 58 entrevistas con periodistas económicos de Brasil, constatamos como las perspectivas sobre la economía de los formadores de opinión afecta la visión sobre la economía de los periodistas. Elaborando en la noción de ilusión de Pierre Bourdieu, exploramos como estos agentes producen golpes noticiosos, son fuentes para logran portadas, y dan forma a las perspectivas económicas. Entre los resultados encontramos que la idea de "meterse con el mercado" jerarquiza a textos y autores. Las fuentes más prestigiosas en la cobertura de la economía en Brasil han pasado por gobiernos, instituciones financieras y provienen del espacio financiero. Los periodistas establecen relaciones recíprocas con estas fuentes prestigiosas, obteniendo golpes noticiosos y entrevistas. Es decir, realizan la ilusión de la profesión y establecen posiciones centrales en el periodismo económico. Los modos de aprendizaje y especialización en economía evidencian la influencia de los agentes del espacio financiero como agentes dominantes en la cobertura económica.

PALABRAS CLAVE: Periodismo económico. Elites. Illusio. Economistas. Finanzas. 
Referências

ABREU, A. A. Jornalistas e jornalismo econômico na transição democrática. In: ABReU, A. A; LATtMAn-Weltman, F; KORNIS, M. A. Mídia e Política no Brasil: jornalismo e ficção. Rio de Janeiro: Editora FGV, 2003.

ABREU, A. A; ROCHA, D. Elas ocuparam as redações: depoimentos ao CPDOC. Rio de Janeiro: Editora FGV, 2006.

BOURDIEU, P. O mercado dos bens simbólicos. In: A Economia das trocas simbólicas. São Paulo: Perspectiva, 1987a. . Campo do poder, campo intelectual e habitus de classe. In: A Economia das Trocas Simbólicas. São Paulo: Perspectiva, 1987 b.

. Sobre o poder simbólico. In: O poder simbólico. Rio de Janeiro: Bertrand Brasil, 1989.

. As regras da arte. São Paulo: Companhia das Letras, 1996.

. Le champ économique. ARSS, n. 119, 1997a.

. Sobre a televisão. Rio de Janeiro: Jorge Zahar, 1997 b.

. Les structures sociales de l'économie. Paris: Seul, 2000.

. Meditações Pascalianas. Rio de Janeiro: Bertrand Brasil, 2001a.

. Pós-escrito 2: A dupla verdade do trabalho. In: Meditações

Pascalianas. Rio de Janeiro: Bertrand Brasil, 2001b.

A distinção: crítica social do julgamento. São Paulo/Porto Alegre: Edusp/Zouk, 2007.

CALDAS, S. Jornalismo econômico. São Paulo: Contexto, 2003.

CHAMPAGNE, P. Le journalisme à l'économie. ARSS, n. 131-132, 2000.

. L'étude des médias et l'apport de la notion de champ. In: PINTO, É. Pour une analyse critique des médias: le débat public en danger. Paris: Éditions du Croquant, 2007.

COMBESSIE, J-C. La méthode em sociologie. Paris: La Decouverte, 2001. 
Jornalistas da economia e homens das finanças: fascinação, ascendência e ilusão profissional

COSTEY, P. L'illusio chez Pierre Bourdieu. Les (més)usages d'une notion et son application au cas des universitaires. Revue Tracés, n. 8, 2005.

DUVAL, J. Critique de la raison journalistique. Paris: Le Seuil, 2004.

KUCINSKI, B. Jornalismo econômico. São Paulo: Edusp, 1996.

LENE, H. O jornalismo de economia no Brasil. Cruz das Almas, BA: Editora UFRB, 2013.

LOUREIRO, M. R. Os economistas no governo: gestão econômica e democracia. Rio de Janeiro: Fundação Getúlio Vargas, 1997.

MATOS, V. Carlos Alberto Sardenberg. Pode mudar presidente, mas a política econômica não muda. Jornal Matéria Prima, Maringá, PR, 25 ago. 2008. Disponível em: http://www.jornalmateriaprima.jex.com.br/entrevista/carlos+alberto+sardenberg++ pode+mudar+presidente+mas+a+politica+economica+nao+muda

NASSIF, L. O jornalismo dos anos 90. São Paulo: Futura, 2003.

NEVEU, E. Sociologia do jornalismo. São Paulo: Loyola, 2006.

PEDROSO NETO, A. J. O espaço dos jornalistas da economia brasileiros gerações, origem social e dinâmica profissional. Revista Pós Ciências Sociais, UFMA, v. 12, 2015.

PEDROSO NETO, A. J; UNDURRAGA, T. The Elective Affinity Between Elite Journalists and Mainstream Economists in Brazil. Journalism Studies, p.2243-2263, 2017.

PEDROSO NETO, A. J; UNDURRAGA, T. Elites do jornalismo econômico brasileiro: gerações, especialização e audiência. In: GRILL, I. G. REIS, E. T. (Org.). Estudos de elites e formas de dominação. São Luís, MA: EDUFMA, no prelo.

PULITI, P. A financeirização do noticiário econômico no Brasil 1989 - 2002. Tese de Doutorado. Escola de Comunicações e Artes, USP, 2009.

QUINTÃO, A-S. F. O jornalismo econômico no Brasil depois de 1964. Rio de Janeiro: Agir, 1987.

RESENDE, J. V. Construtores do jornalismo econômico: da cotação do boi ao congelamento dos preços. São Paulo: Ícone, 2005. 
RIBEIRO, E; PASCHOAL, E. Jornalistas brasileiros: quem é quem no jornalismo de economia. São Paulo: Mega Brasil e Call Comunicações, 2005.

ROSA, T. F. M. A cobertura do BNDES nos governos FHC e Lula; as relações entre os campos do pensamento econômico e jornalístico na imprensa brasileira. Dissertação de Mestrado. Programa de Pós-Graduação em Comunicação e Sociedade, Universidade Federal do Tocantins, 2019.

ROSA, T. F. M.; PEDROSO NETO, A. J. A cobertura do BNDES nos Governos FHC e Lula bases ortodoxas nas narrativas sobre privatizações e PAC. Revista Observatório, vol. 5, n. 4, 2019.

SCHUDSON, M. The power of news. Cambridge, Mass: Harvard University Press, 1995.

SOUZA, T. S. M. O jornalismo econômico e a cobertura da previdência nos anos de discussões das reformas. Dissertação de Mestrado. Programa de Pós-Graduação em Comunicação e Sociedade, Universidade Federal do Tocantins, 2019.

STARKMAN, D. The watchdog that didn't bark. New York: Columbia University Press, 2014.

TEMMAR, M; ANGERMULLER, J; LEBARON, F. Les discours de l'économie. Paris: Curapp-Ess Editions, 2013

UNDURRAGA, T. Making news, making the economy: technological change and financial pressures in Brazil. Journal of Cultural sociology, v. 11, p.77-96, 2017a. . Making news of value: exploiting dissonances in economic journalism. Journal of cultural economy, p.510-523, 2017b.

VELOSO, V. L. Crise econômica e desoneração do IPI nos jornais brasileiros: silêncio dos economistas e quadros performativos. Dissertação de Mestrado. Programa de Pós-Graduação em Comunicação e Sociedade, Universidade Federal do Tocantins, 2018.

Recebido em 27/09/2019. Aprovado em 31/10/2019. 